\title{
Analysis on the Mechanical Characteristics and Energy Conversion of Sandstone Constituents under Natural and Saturated States
}

\author{
Xinrong Liu ${ }^{1,2}$ and Jun Liu, ${ }^{1,2}$ \\ ${ }^{1}$ College of Civil Engineering, Chongqing University, Chongqing 400045, China \\ ${ }^{2}$ Key Laboratory of New Technology for Construction of Cities in Mountain Area (Chongqing University), \\ Ministry of Education, Chongqing 400030, China
}

Correspondence should be addressed to Jun Liu; 517694008@qq.com

Received 15 June 2016; Revised 11 August 2016; Accepted 14 August 2016

Academic Editor: Hossein Moayedi

Copyright (C) 2016 X. Liu and J. Liu. This is an open access article distributed under the Creative Commons Attribution License, which permits unrestricted use, distribution, and reproduction in any medium, provided the original work is properly cited.

Given that apparent differences exist between physical and mechanical properties of sandstone constituents under natural and saturated states, uniaxial and triaxial tests of sandstone specimens taken from a deep tunnel in Chongqing under the two states were, respectively, conducted in the laboratory. Analysis on the energy conversion of sandstone constituents under natural and saturated states reveals the varying strain energy conversion mechanisms under the two different conditions. It shows that water saturation has significant effects on the strength and deformation characteristics of sandstone constituents. The load bearing capacity and nondeformability decrease once the sandstone constituents are saturated. The strength weakening due to water in saturated specimens mainly takes place after the dilatancy stress $\sigma_{\mathrm{cd}}$ and reaches its maximum at the peak stress $\sigma_{f}$. Strain energies of sandstone constituents under the saturated state are lower than those under the natural state, which indicates that water reduces the strain energy absorption. The strain energy of specimens at the peak stress point under the two states has a good linear positive correlation with the confining pressure. Moreover, the fitting curve of the case under the natural state has a higher slope, which means that the strain energy under such state is more sensitive to the confining pressure than that under the saturated state.

\section{Introduction}

Extensive tunnel projects, where issues related to underground water often strike negative impacts on the construction, such as water inrush and water burst [1-3], have been built along with the vigorous development of the highspeed railway, high way, and subway in China. Analyzing and understanding mechanical properties of the surrounding rock is fundamental to manage these engineering disasters. The tunnel construction often penetrates multiple layers of formations, and the physical and mechanical properties of rock with different water contents vary significantly [4-6]. Many scholars have carried on extensive studies on this subject. Hawkins et al. $[4,5]$ conducted uniaxial tests on 35 types of British sandstones to analyze the origin of differences of the strength, tangent, and secant Young's modulus between specimens under the dry and the saturated states. Vásárhelyi and Ván [6] found that water saturation of $1 \%$ could greatly decrease the rock strength and they attempted to propose a method to evaluate the sensitivity of sandstones to water saturation based on the published data. Sass [7] proposed five different methods to measure the water content of rock. Thill et al. [8] and Louis et al. [9], respectively, studied the anisotropy of parameters of granite, marble, and sandstones under dry and saturated states. Based on the studies mentioned above, it is safe to say the researches focusing on the mechanical characteristic differences existing at each stage of the rock deformation and failure processes between sandstones under natural and saturated states are relatively insufficient. However, different changes have happened to the mechanical properties of natural and saturated sandstones involved in the construction, long before geological hazards, such as rock mass instability and water burst, occur in the underground projects, like tunnels. 
Furthermore, previous studies on rocks with different water contents mainly focused on the change of physical properties and rarely analyzed the difference in view of energy conversion. The law of thermodynamics states that the energy conversion is the essence of the physical process that all matter is going through and the material damage is an energy-driven instability phenomenon of the equilibrium. The deformation and damage process of rock materials, which is all along accompanied by the energy accumulation, dissipation, and release, is an overall process of energy transfer and conversion [10, 11]. So far, more and more scholars have studied the mechanical behavior characteristics of rock from perspectives of energy. Zhang et al. [12] and Lindqvist [13] have studied the mechanism of energy dissipation and fracturing of rock materials under impact loads and dynamic loads. Tsoutrelis et al. [14-16] studied the energy dissipation during the damage evolution, the strength, and the failure criteria, based on the uniaxial and triaxial tests. Bagde et al. $[17,18]$ studied the patterns of energy dissipation and release during the damage evolution and cracking of rock materials in the loading and unloading tests. Accordingly, the essential reasons behind the differences between physical and mechanical characteristics of rocks with different water contents reflected in the uniaxial and triaxial tests can be revealed based on the principles of energy conversion [19].

This study targets on the sandstone constituents taken from a deep tunnel in Chongqing and conducts uniaxial and triaxial tests on sandstone specimens under natural and saturated states. The mechanical characteristics of rocks under the two test conditions are discussed, especially the effects of water saturation on the strength and deformation characteristics of sandstone constituents. In the meantime, from the perspective of energy, the energy accumulation and dissipation as well as relevant parameters at the peak strength point have been analyzed, which provides insights of the energy dissipation and release mechanism during the damage evolution process of sandstones. Moreover, in a view of energy, the feature evolution mechanism of energy accumulation and dissipation in the deformation and damage process of sandstone constituents under the two conditions is analyzed. Finally, based on the mineral composition analysis and Mohr-Coulomb theory, the deterioration mechanism of sandstone constituents subjected to water is concluded. The findings of this research are of engineering significance to the stability evaluation and prediction of underground evacuation, such as tunnels, and guidance are also offered for the design, construction, and hazard control of the project.

\section{Materials and Methods}

2.1. Sample Preparation. The rock sample in this paper is an intact sandstone of the upper Triassic Xujiahe formation, taken from a deep tunnel in Chongqing at the depth of $600 \mathrm{~m}$. It is green grey, medium-fine grained with the particle size of $0.1 \sim 0.5 \mathrm{~mm}$ and presents a block structure. The SC300 auto core drilling machine, as shown in Figure 1(a), in the State Key Laboratory of Coal Mine Disaster Dynamics and Control, A District, Chongqing University, was used for coring and the M250 grinder, as shown in Figure 1(b), for fine grinding. With the error in diameter less than $0.1 \mathrm{~mm}$ and the cross section roughness less than $0.025 \mathrm{~mm}$, cylindrical specimens were made out of the sandstone sample. The specimen diameter $D$ was $50 \mathrm{~mm}$, and the height $H$ was $100 \mathrm{~mm}$, which indicated a height-diameter ratio of $2: 1$. To study different mechanical characteristics and energy mechanisms of sandstone constituents under natural and saturated states, specimens were divided into two types: one remaining its "natural" condition and the other one artificially "saturated." Each type contained six groups and each group three specimens. One of the six groups in each type was used as standby. The sandstone specimens of the "saturated" type were saturated using the SRH-type intelligent concrete vacuum water saturation instrument, as shown in Figure 1(c). Part of the sandstone specimens are shown in Figure 1(d).

2.2. Test Methods. For the saturated-type specimens, the first step was water saturation. The specimen was put into the intelligent concrete vacuum water saturation instrument. The instrument would automatically soak and saturate the specimen in water for 24 hours after evacuating with a negative pressure of $-80 \mathrm{kPa}$ for four hours. Then, sandstone specimens of the two types were, respectively, going through the uniaxial and triaxial tests. All the tests followed the guideline suggested by the American Society for Testing and Materials (ASTM) in 2014 [20] and were accomplished using the TRIAXIAL CELL V4.0 "multifield coupling rock triaxial test apparatus," developed by the Lille 1 University of Science and Technology and manufactured by the Top Industrie Co. Ltd. The appearance of the apparatus is shown in Figure 2(a).

The test procedure was concluded as follows: the sandstone specimen was first wrapped with a rubber case, then placed inside the pressure chamber (as is shown in Figure 2(b)), and finally connected with the axial displacement sensor and circumferential strain measuring instrument. The axial strain was measured using two linear variable differential transformers (LVDT), while the hoop strain by the radial strain gauge (RSG) set at the central part of the specimen. The uniaxial compression test was axial displacement-controlled with a displacement change rate of $0.02 \mathrm{~mm} / \mathrm{min}$, and the specimen was subjected to axial loading until it was broken. For the triaxial compression test, the operation before loading was the same as in the uniaxial compression test. After the pressure chamber was closed, the confining pressure determined according to the hydrostatic pressure was first applied with a loading rate of $2 \mathrm{MPa} / \mathrm{min}$, and the specimen was then loaded axially until it was broken. The loading was also controlled by the axial displacement with a change rate of $0.02 \mathrm{~mm} / \mathrm{min}$. The triaxial compression test was proceeded under an undrained condition, for the samples were taken from a deep tunnel and thus had been originally enclosed. In addition, according to Brown and Hoek [21], and Jing et al. [22], as the buried depth was $600 \mathrm{~m}$, the confining pressure would be about $16.2 \mathrm{MPa}$, which was then set as $15 \mathrm{MPa}$ for convenience. In fact, four levels of confining pressures were tested in the triaxial test, namely, $15 \mathrm{MPa}, 25 \mathrm{MPa}$, $35 \mathrm{MPa}$, and $45 \mathrm{MPa}$. In the meantime, to analyze the rock property with varying water contents, specimens were tested, 


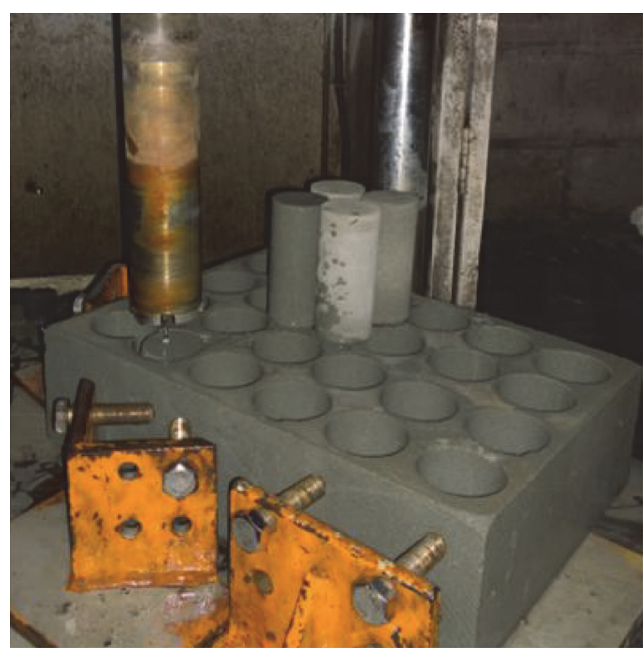

(a) SC-300 machine

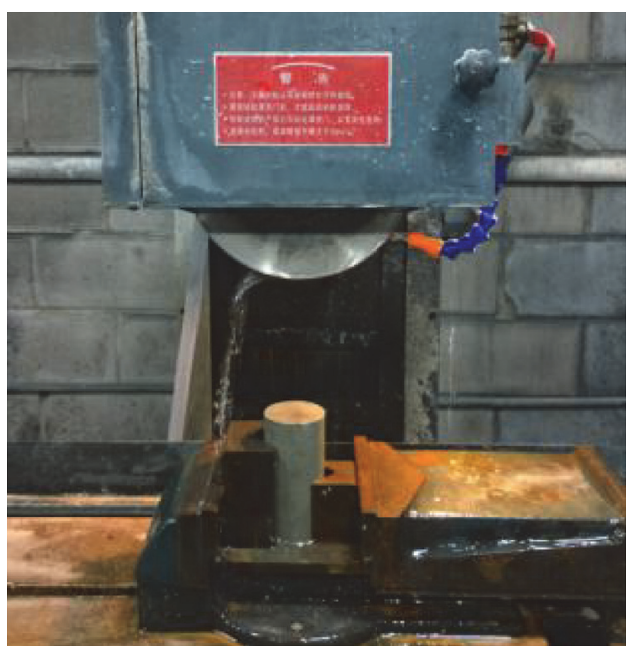

(b) M250 grinder

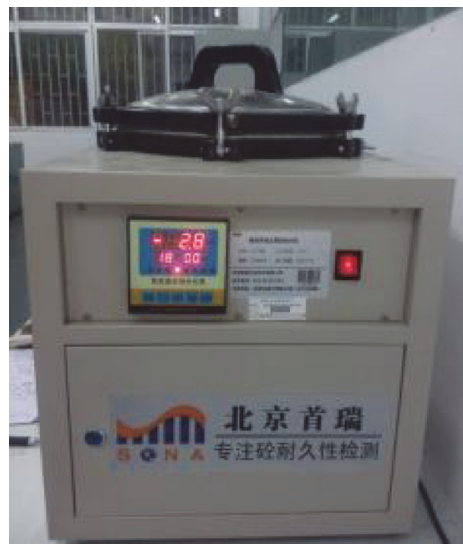

(c) SRH-type instrument

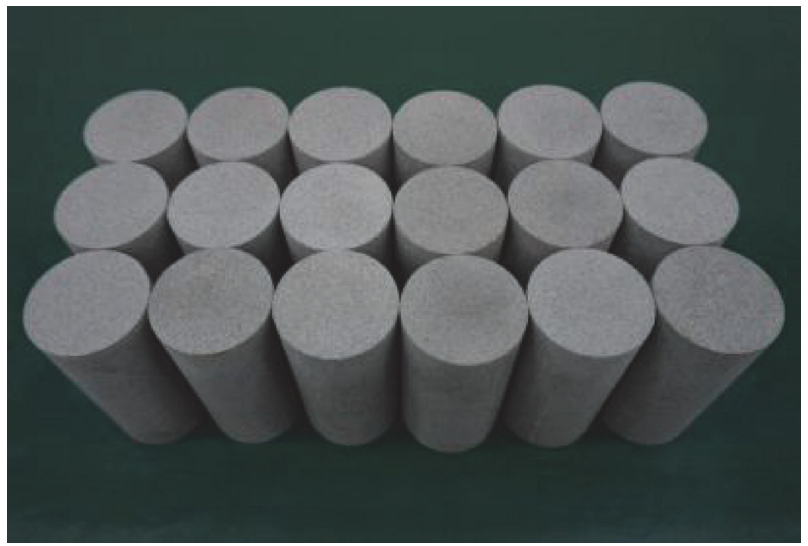

(d) Sandstone specimens

Figure 1: Part of the test apparatus and sandstone specimens.

respectively, under the natural state and saturated state. By calculation, the average water content of the specimens under natural state is $1.619 \%$, and that under saturated state is $5.663 \%$.

2.3. Principles of Energy Calculation. The rock specimen deforms due to the external force in the test. Assuming there is no heat exchange between the specimen and the surroundings, which means a closed system, the total strain energy input from the working of the external force, $U$, can be calculated according to the first law of thermodynamics [10]:

$$
U=U_{e}+U_{d}
$$

where $U_{e}$ is the releasable elastic strain energy; $U_{d}$ is the dissipated energy.

The relationship between the elastic energy and the dissipated energy is shown in Figure 3.
Under the state of the conventional triaxial compression, $\sigma_{2}=\sigma_{3}$, and hence the total strain energy $U$ at any moment $(t)$ during the test can be calculated as follows:

$$
U=\int_{0}^{\varepsilon_{1}^{t}} \sigma_{1} d \varepsilon_{1}+2 \int_{0}^{\varepsilon_{3}^{t}} \sigma_{3} d \varepsilon_{3}
$$

where $\varepsilon_{i}^{t}(i=1,3)$ refers to the strain at any moment $(t)$ in the stress-strain curve

$$
U_{e}=\frac{1}{2} \sigma_{1} \varepsilon_{1}^{e}+\sigma_{3} \varepsilon_{3}^{e}
$$

For convenience of calculation in the engineering application, (3) can be rearranged as follows:

$$
U_{e}=\frac{1}{2 E_{0}}\left[\sigma_{1}^{2}+2 \sigma_{3}^{2}-2 \mu\left(\sigma_{3}^{2}+2 \sigma_{1} \sigma_{3}\right)\right],
$$

where $E_{0}$ and $\mu$ are, respectively, the initial Young's modulus and Poisson's ratio of the specimen. 


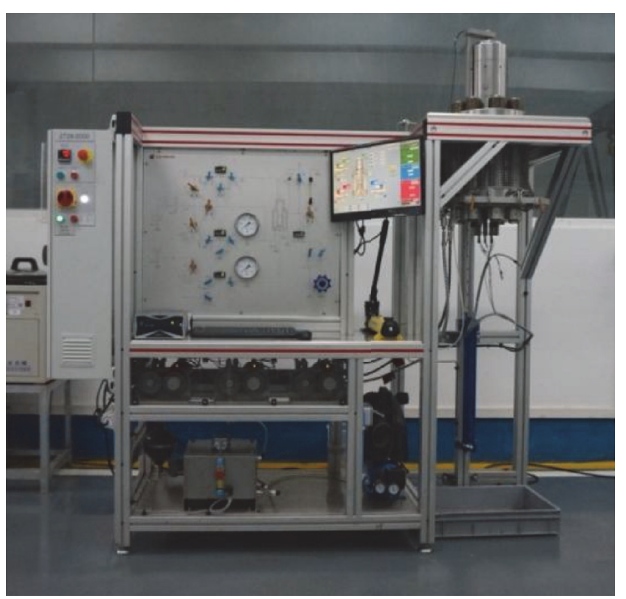

(a) Appearance of test apparatus

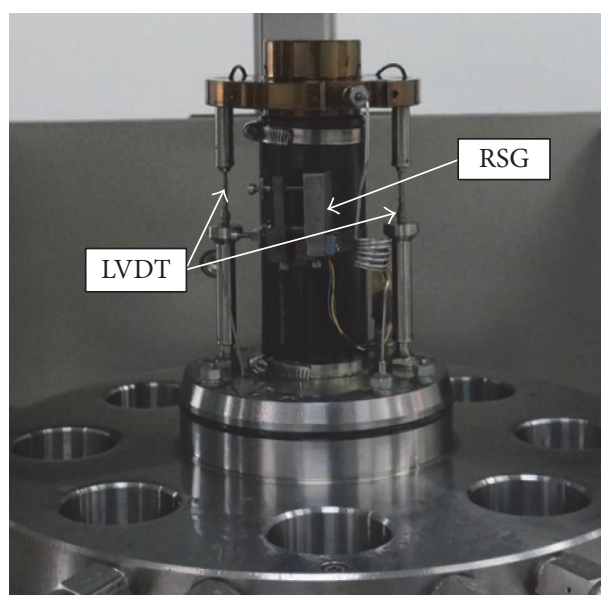

(b) Pressure chambers

FIGURE 2: The multifield coupling rock triaxial test apparatus.

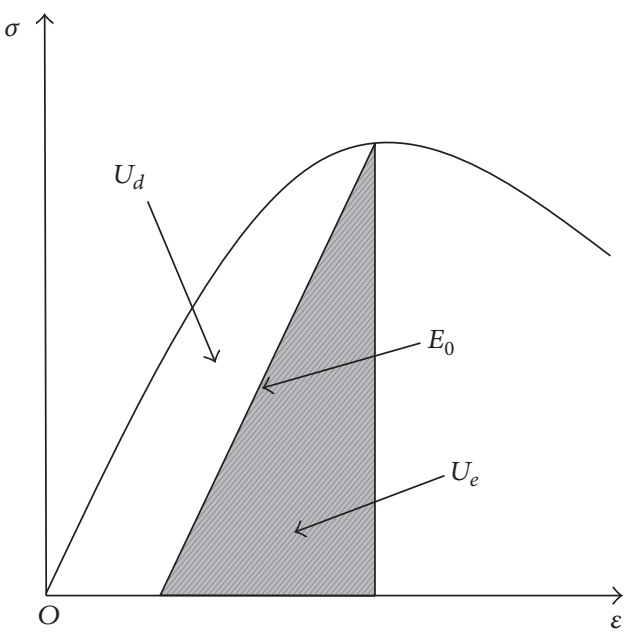

FIGURE 3: Relationship between the elastic energy and the dissipated energy [10].

In addition, the total strain energy of the specimen, $U$, can also be described as follows:

$$
U=U_{1}+U_{3}+U_{0},
$$

where $U_{1}$ is the strain energy absorbed from the compression caused by the axial load $\sigma_{1} ; U_{3}$ is the strain energy derived from the loading and unloading of the confining pressure $\sigma_{3}$; $U_{0}$ is the strain energy absorbed under the hydrostatic state of stress.

At any moment $(t)$ in the test, the absorbed axial strain energy $U_{1}$ and the strain energy dissipated due to the negative working done by the confining pressure $U_{3}$ can both be calculated by integrating based on the stress-strain curve:

$$
\begin{aligned}
& U_{1}=\int_{0}^{\varepsilon_{1}^{t}} \sigma_{1} d \varepsilon_{1}, \\
& U_{3}=\int_{0}^{\varepsilon_{3}^{t}} \sigma_{3} d \varepsilon_{3},
\end{aligned}
$$

where $\varepsilon_{1}^{t}$ is the axial strain in the stress-strain curve at any moment $(t) ; \varepsilon_{3}^{t}$ is the hoop strain at any moment $(t)$.

According to the definition of the definite integral, solving (6) can be achieved by solving the following:

$$
\begin{aligned}
& U_{1}=\sum_{i=1}^{n} \frac{1}{2}\left(\sigma_{1}^{i}+\sigma_{1}^{i+1}\right)\left(\varepsilon_{1}^{i+1}-\varepsilon_{1}^{i}\right), \\
& U_{3}=\sum_{i=1}^{n}\left(\sigma_{3}^{i}+\sigma_{3}^{i+1}\right)\left(\varepsilon_{3}^{i+1}-\varepsilon_{3}^{i}\right),
\end{aligned}
$$

where $\sigma_{1}^{i}$ and $\varepsilon_{1}^{i}$ are, respectively, the stress and strain at each point of the stress-strain curve.

$U_{0}$ can be calculated based on the elastic mechanics:

$$
U_{0}=\frac{3(1-2 \mu)}{2 E}\left(\sigma_{3}^{0}\right)^{2} .
$$

Accordingly, the dissipated energy $U_{d}$ can be described as follows:

$$
U_{d}=U_{1}+U_{3}+U_{0}-U_{e}
$$

Energy calculation equations for the uniaxial compression test are shown in the following:

$$
\begin{aligned}
U & =\int_{0}^{\varepsilon_{1}^{t}} \sigma_{1} d \varepsilon_{1}, \\
U_{e} & =\frac{1}{2} \sigma_{1} \varepsilon_{1}^{e}=\frac{\sigma_{1}^{2}}{2 E_{0}}, \\
U_{d} & =\int_{0}^{\varepsilon_{1}^{t}} \sigma_{1} d \varepsilon_{1}-\frac{\sigma_{1}^{2}}{2 E_{0}} .
\end{aligned}
$$




\section{Experimental Results and Analysis}

\subsection{Uniaxial Compressive Test}

3.1.1. Deformation Characteristics. Figure 4 shows the stressstrain curves of one group of the uniaxial compression tests under the natural state and one group under the saturated state.

The following can be concluded from Figure 4:

(1) The deformation and damage process of sandstone specimens under natural and saturated states can both be divided into five regions: the crack closure region $(O-A)$, elastic region $(A-B)$, stable crack growth region $(B-C)$, crack calescence region $(C-D)$, and postpeak region $(D-E)[23,24]$, and the specimens under the two states both exhibit brittleness in the postpeak region while the brittle characteristic is more obvious under the saturated state.

(2) Water saturation has great effects on the strength and deformation characteristics of sandstone specimens. Under the natural state, the uniaxial compressive strengths of sandstone specimens range from $54.2 \mathrm{MPa}$ to $56.1 \mathrm{MPa}$, with an average of $55.3 \mathrm{MPa}$, while, under the saturated state, the strengths vary between $47.4 \mathrm{MPa}$ and $52.1 \mathrm{MPa}$, with an average of 49.1 MPa, which indicates that the strength of sandstone specimens has been reduced by water [5]. In consideration of the definition of the softening coefficient, the ratio of the average compressive strength of saturated rock to that of rock under natural state in this paper is defined as the equivalent softening coefficient, $\eta_{c}^{\prime}$, which is 0.8879 in this case. Moreover, the peak axial strains of sandstone specimens under the natural state range from $0.598 \%$ to $0.688 \%$, with an average of $0.645 \%$, while those of saturated specimens are $0.715 \sim 0.762 \%$, with an average of $0.740 \%$, which indicates that the peak axial strain generally grows after water saturation [19].

(3) Water saturation also affects the deformation parameters of rock specimens. Under the natural state, Young's moduli of sandstone specimens are 9.52 10.22 GPa, averaging 9.74 GPa, while under the saturated state, they are $7.74 \sim 8.02 \mathrm{GPa}$, averaging $7.90 \mathrm{GPa}$. This shows that the load bearing capacity and nondeformability of rock decrease after water saturation. In addition, Poisson's ratios of specimens under the natural state are 0.172 0.190, averaging 0.176 , while those of saturated specimens range from 0.213 to 0.242 , averaging 0.224 , which states that the lateral deformation becomes greater.

3.1.2. Energy Conversion Characteristics. The values of strain energy at the peak points in the stress-strain curves can be calculated from the uniaxial compression test results of sandstone specimens under natural and saturated states, according to (1) and (10), and are shown in Table 1.
TABLE 1: Strain energy at peak stress point under uniaxial compression test $\left(\mathrm{kJ} \cdot \mathrm{m}^{-3}\right)$.

\begin{tabular}{lcccccc}
\hline \multirow{2}{*}{$\begin{array}{l}\text { Strain } \\
\text { energy }\end{array}$} & \multicolumn{3}{c}{ Natural state } & \multicolumn{3}{c}{ Saturated state } \\
& I-1 & I-2 & I-3 & II-1 & II-2 & II-3 \\
\hline$U$ & 165.24 & 158.22 & 171.71 & 138.26 & 148.53 & 146.75 \\
$U_{e}$ & 135.45 & 135.87 & 128.57 & 111.75 & 112.89 & 121.17 \\
$U_{d}$ & 29.79 & 22.35 & 43.15 & 26.51 & 35.64 & 25.58 \\
\hline
\end{tabular}

According to Table 1 , the averages of $U, U_{e}$, and $U_{d}$ at the peak points under the natural state are, respectively, $165.06 \mathrm{~kJ} / \mathrm{m}^{3}, 133.30 \mathrm{~kJ} / \mathrm{m}^{3}$, and $31.76 \mathrm{~kJ} / \mathrm{m}^{3}$, and those under the saturated state are $144.51 \mathrm{~kJ} / \mathrm{m}^{3}, 115.27 \mathrm{~kJ} / \mathrm{m}^{3}$, and $29.24 \mathrm{~kJ} / \mathrm{m}^{3}$. It is shown that most of the energy absorbed before the stress reaches its peak is stored as the elastic strain energy and only a few are dissipated. Moreover, the three kinds of strain energy all decrease after water saturation, which indicates that water reduces the strain energy absorption of sandstone specimens [19]. To further analyze the energy conversion in each region of the uniaxial compression process of sandstone constituents under natural and saturated states, the axial stress-axial strain-strain energy curves of sandstone constituents under the two states are plotted and shown in Figure 5.

The following can be seen from Figure 5:

(1) The elastic strain energy and dissipated energy in the crack closure $(O-A)$ and elastic region $(A-B)$ are relatively small under both states, while the elastic strain energy is slightly higher than the dissipated energy.

(2) In the stable crack growth region $(B-C)$, the elastic strain energy of sandstone specimens under the two states increases faster than those in previous regions. The elastic strain energy curve grows almost parallel with the total strain energy curve and the increase in the dissipated energy is small, which means in this region the energy absorbed by the rock specimen from the outside is mainly used for the elastic deformation of the loading bearing structure inside the rock.

(3) In the crack coalescence region $(C-D)$, the dissipated energy begins to rise rapidly, although the absorbed energy is still mainly stored as the elastic strain energy. It is indicated that in this region massive microcracks occur in sandstone specimens and plastic deformation grows fast.

(4) In the postpeak region (D-E), the dissipated energy increases rapidly with the elastic strain energy stored in the sandstone specimen fast decreasing, and eventually the former exceeds the latter. This is mainly because the massive elastic strain energy absorbed by the sandstone specimen can be released in a great amount within a short period in the forms of the kinetic energy and the friction energy, and so forth, and meanwhile the dissipated energy grows greatly due to plastic deformation and the linking and sliding 


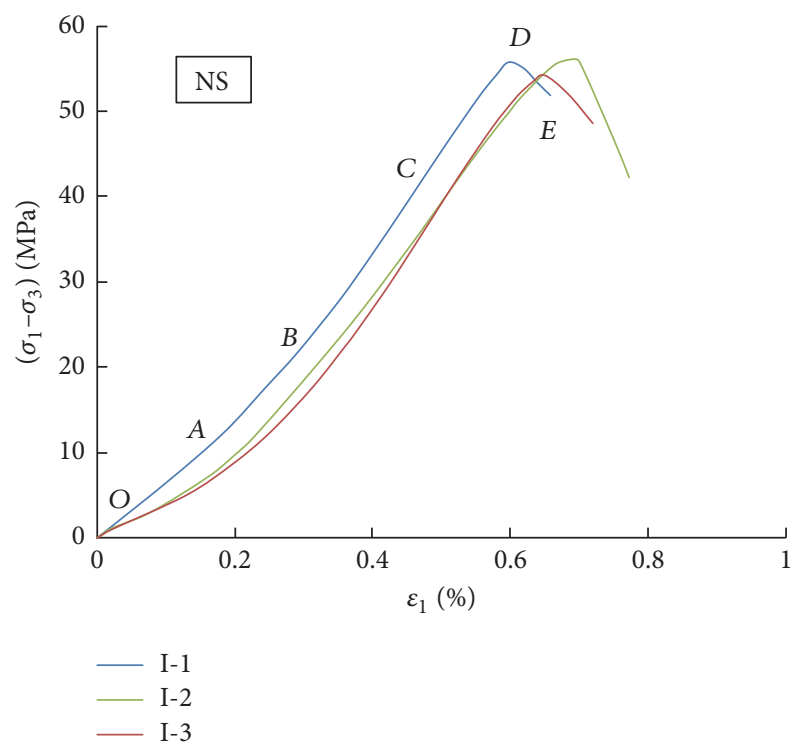

(a)

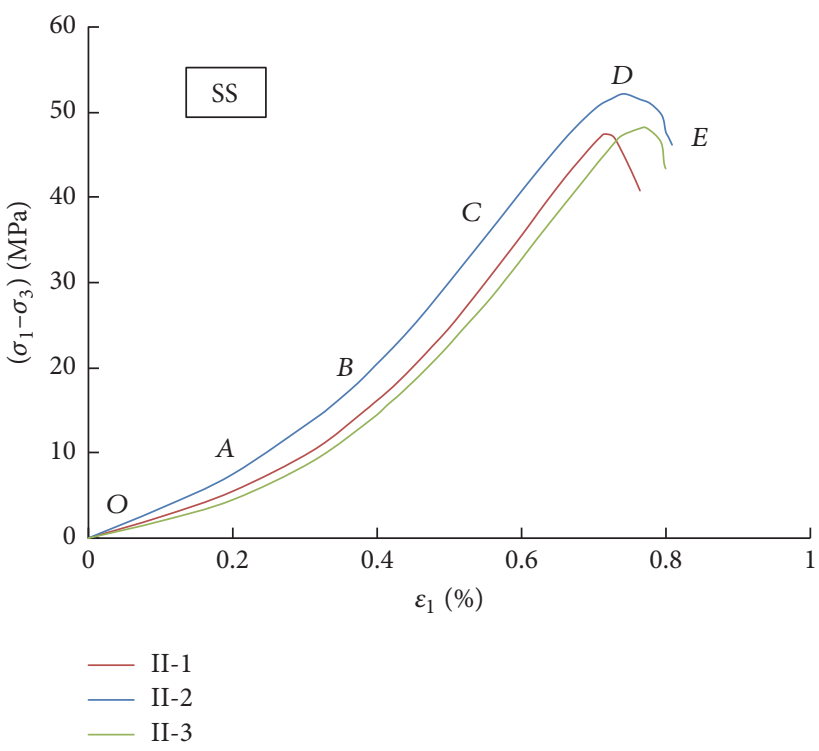

(b)

FIGURE 4: The stress-strain curves of uniaxial compression tests under natural and saturated states. Note: NS refers to "under the natural state" and SS refers to "under the saturated state."

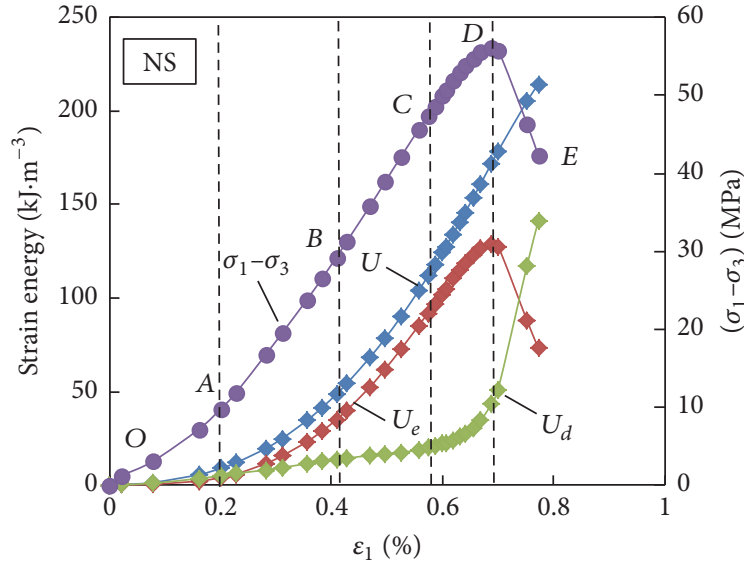

(a)

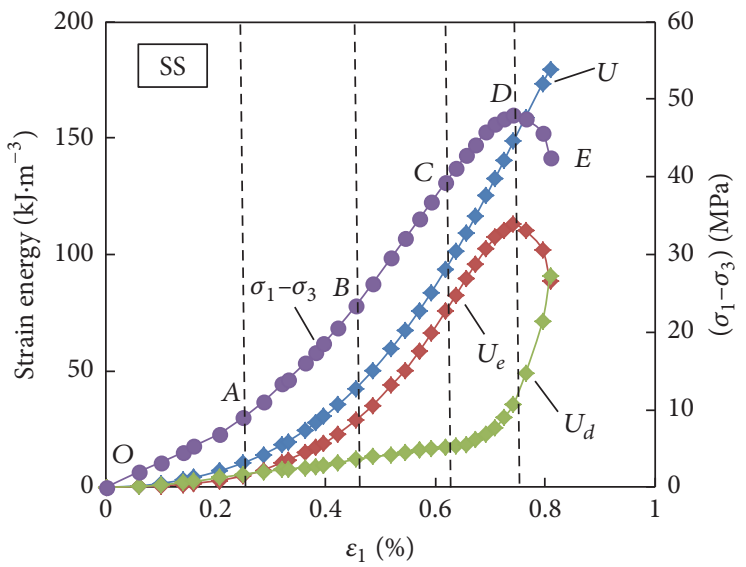

(b)

FIGURE 5: The energy conversion curves of uniaxial compression tests.

of macrofractures [11]. The rock strength gradually reduces and at last the specimen fails.

It can also be concluded from Figure 5 that the energy conversion patterns of sandstone specimens under natural and saturated states are generally similar, although they vary greatly in different regions of the process. The change patterns of the three kinds of strain energy, $U, U_{e}$, and $U_{d}$, of natural and saturated specimens are compared and shown in Figure 6.

Figure 6 shows the following:

(1) The total strain energy $U$ of the specimen under the natural state increases faster with the growth of the axial strain than that of the saturated specimen and reaches a greater final value.
(2) In the prepeak region, the elastic strain energy of the specimen under the natural state grows with the axial strain at a higher rate than that under the saturated state. However, in the postpeak region, the release rate of the elastic strain energy $U_{e}$ of the saturated sandstone exceeds that of the specimen under the natural condition. The saturated specimen fails with a relatively small postpeak axial strain, mainly because of the water softening, which stimulates the release of the elastic strain energy $U_{e}$.

(3) Comprehensively considering Figures 5 and 6, it is safe to say that the differences of the dissipated energy $U_{d}$ between specimens under natural and saturated states in the region of $O-A, A-B$, and $B-C$ are relatively minor. In $C-D$, the dissipated energy $U_{d}$ of specimens 


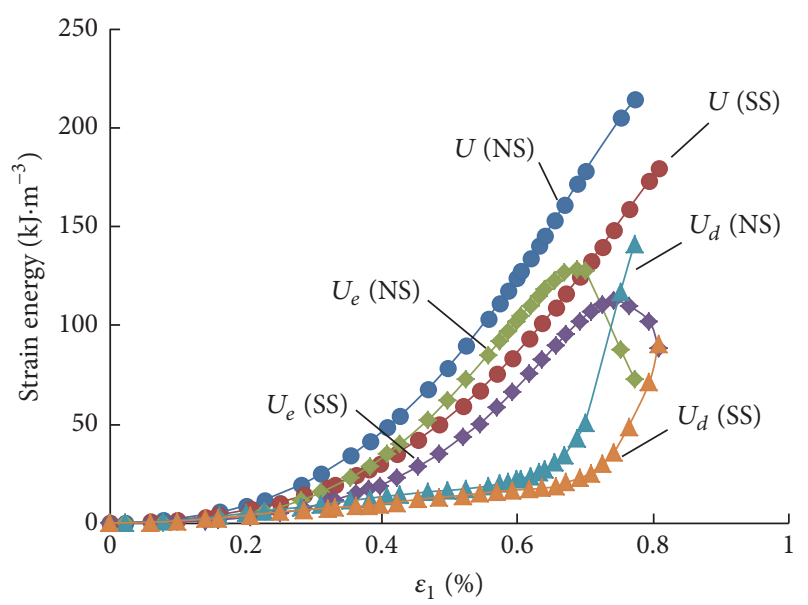

Figure 6: Comparison of energy conversion curves under natural and saturated states.

under the natural state grows faster with the axial strain than that of saturated specimens. However, in $D-E$, the increase rate of the dissipated energy $U_{d}$ of saturated specimens is slightly higher than that under the natural state, due to the water softening and the easier propagation and linking of microcracks and damages inside the rock under the effect of water. Yet, under the uniaxial stress condition, the promoting effect of water on crack propagation is relatively weak, because the saturated sandstone specimen has reasonable permeability coefficients and water inside the rock can be easily discharged under such conditions, which leads to a smaller pore pressure generated inside the rock. Hawkins and McConnell [4] and Atkinson and Cook [25] have also found and discussed this issue in their studies.

\subsection{Triaxial Compressive Test}

3.2.1. Deformation Characteristics. The stress-strain curves of sandstone specimens under natural and saturated states for the triaxial compression test are shown in Figure 7.

The following is shown in Figure 7:

(1) Under the effect of the confining pressure, the five regions occurring in the uniaxial compression repeat in the triaxial compression process of specimens under the two states. However, under the triaxial stress condition, the stress-strain curve exhibits apparent plasticity and the postpeak curve presents a certain degree of ductility, instead of a sharp decline shown in the uniaxial compression. Moreover, the ductility intensifies with the increase in the confining pressure [19]. Under the natural state, the sharp stress decline occurs under the confining pressure of $15 \mathrm{MPa}$, while no obvious stress decline occurs with the confining pressure of $25 \mathrm{MPa}, 35 \mathrm{MPa}$, and $45 \mathrm{MPa}$. However, for saturated sandstone specimens, the significant postpeak stress drop shows up under confining pressures below $45 \mathrm{MPa}$. This indicates that,
TABLE 2: Feature point stress for triaxial tests under natural and saturated states.

\begin{tabular}{cccccc}
\hline States & Confining & \multicolumn{4}{c}{ Feature point stress values/MPa } \\
& pressure/Mpa & $\sigma_{\mathrm{cc}}$ & $\sigma_{\mathrm{ci}}$ & $\sigma_{\mathrm{cd}}$ & $\sigma_{f}$ \\
\hline \multirow{4}{*}{ NS } & 15 & 24.16 & 56.41 & 89.66 & 110.82 \\
& 25 & 27.33 & 66.83 & 103.33 & 131.67 \\
& 35 & 33.20 & 77.49 & 121.79 & 150.99 \\
& 45 & 34.60 & 90.00 & 144.40 & 178.00 \\
\hline \multirow{4}{*}{ SS } & 15 & 18.09 & 49.22 & 80.86 & 100.44 \\
& 25 & 23.03 & 61.57 & 98.61 & 125.14 \\
& 35 & 30.07 & 73.67 & 117.27 & 145.34 \\
& 45 & 30.05 & 82.13 & 131.21 & 160.26 \\
\hline
\end{tabular}

with the abundant presence of water, the propagation of cracks inside the rock is accelerated due to the pore pressure generated in some damage area by the compression of the rock matrix, which leads to high tendency of sharp stress decline after the peak stress.

(2) In the triaxial compression, the peak strain of specimens increases with the rising confining pressure. As the confining pressure grows from $15 \mathrm{MPa}$ to $45 \mathrm{MPa}$, for specimens under the natural state, the peak strain increases from $0.875 \%$ to $1.497 \%$, while the peak strain of the saturated specimen changes from $0.798 \%$ to $1.362 \%$. Under equal confining pressures, the peak strain of the saturated specimen is lower than that of the natural-state specimen, which is different from the results of uniaxial compression tests and may be attributed to the combined effect of water and confining pressures.

(3) With the confining pressure growing from $15 \mathrm{MPa}$ to $45 \mathrm{MPa}$, the peak stresses of natural-state specimens are, respectively, $110.8 \mathrm{MPa}$, 131.7 MPa, 151.0 MPa, and 178.0 MPa, while those of saturated specimens are 100.4 MPa, 125.1 MPa, 145.3 MPa, and 160.3 MPa. The corresponding equivalent softening coefficients, $\eta_{c}^{\prime}$, are $0.9023,0.9494,0.9603$, and 0.8988 , which leads to the finding that the equivalent softening coefficient in triaxial compression is higher than that in uniaxial compression.

3.2.2. Feature Point Stress. The stresses at the four feature points for the five regions (see Figure 5), namely, the compression closure stress $\sigma_{\mathrm{cc}}(A)$, the crack initiation stress $\sigma_{\mathrm{ci}}(B)$, the dilatancy stress $\sigma_{\mathrm{cd}}(C)$, and the peak stress $\sigma_{f}$ $(D)$, of triaxial compression tests under different confining pressures, are shown in Table 2.

Based on Table 2, the relationship between the feature point stress and the confining pressure is shown in Figure 8.

The following can be seen from Table 2 and Figure 8:

(1) $\sigma_{\mathrm{cc}}$ and $\sigma_{\mathrm{ci}}$ of specimens under natural and saturates states are similar, which indicates that water slightly works in the crack closure and the crack initiation regions. $\sigma_{\mathrm{cc}}$ and $\sigma_{\mathrm{ci}}$ of the natural-state specimen are 


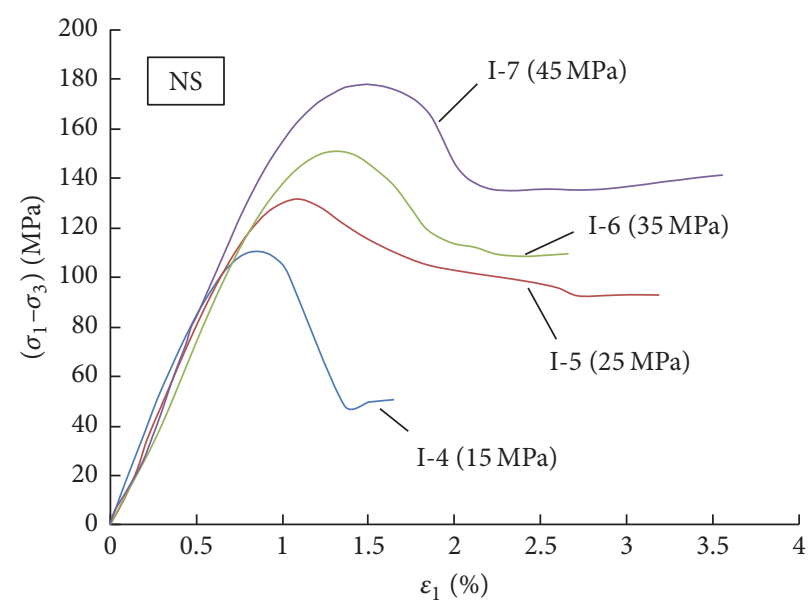

(a)

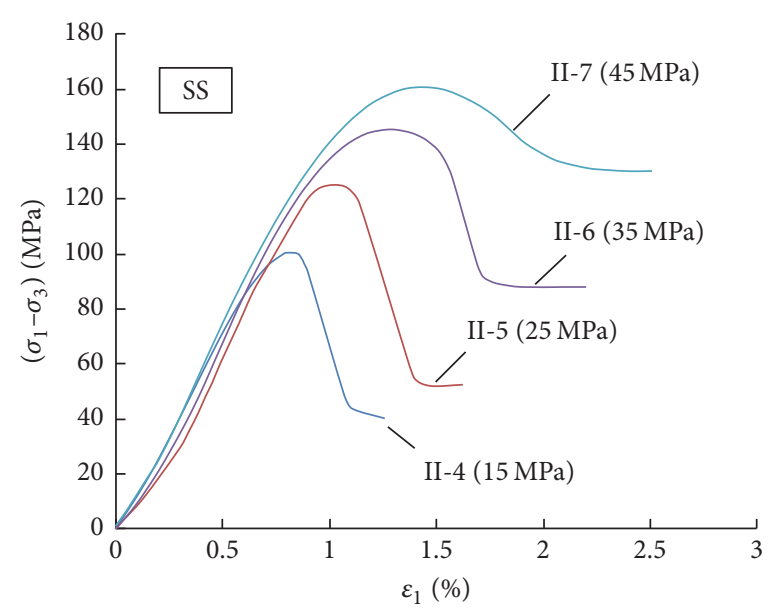

(b)

FIGURE 7: The stress-strain curves of triaxial compression tests under natural and saturated states.

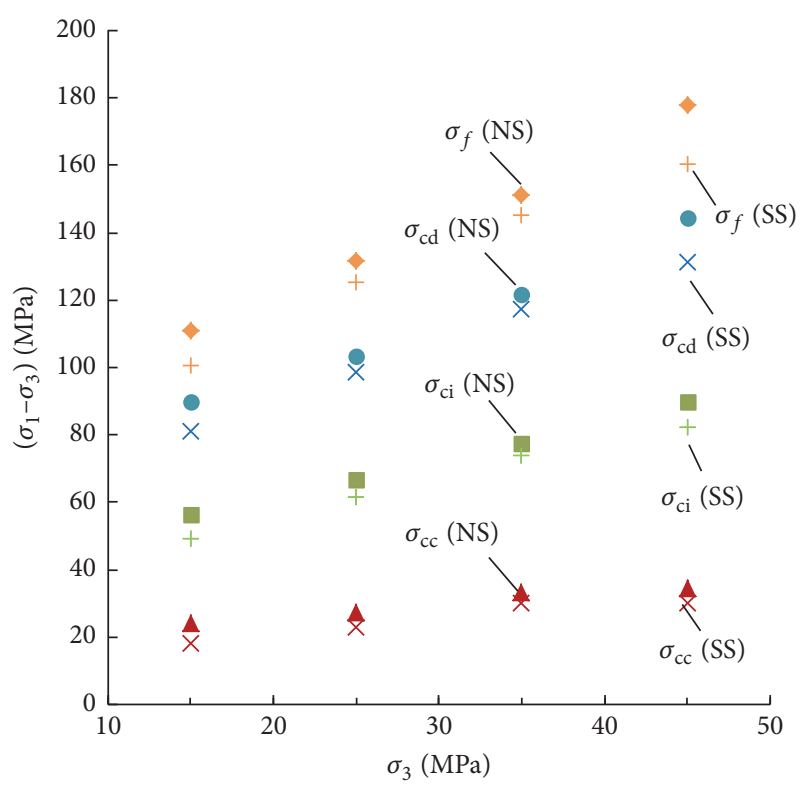

FIGURE 8: The feature point stress versus the confining pressure.

only slightly higher than those of the saturated ones under all confining pressures.

(2) The gaps between $\sigma_{\mathrm{cd}}$ and $\sigma_{f}$ under the two states are larger, with $\sigma_{\mathrm{cd}}$ and $\sigma_{f}$ under the natural state exceeding those of saturated specimens under all confining pressures. This means the strength weakening effect of water in saturated sandstones mainly takes place after the dilatancy stress $\sigma_{c d}$ and reaches its top level at the peak stress $\sigma_{f}$. Hence, the water-saturated sandstones in projects such as tunnel excavation should be supported as soon as possible, in order to limit the stress within a relatively small value and avoid tunnel instability followed by water inrush and burst. Moreover, $\sigma_{\mathrm{cd}}$ and $\sigma_{f}$ of the natural-state specimen increase faster with the confining pressure than those of the saturated sandstone, and hence the gaps of $\sigma_{\mathrm{cd}}$ and $\sigma_{f}$ under the two state tend to grow with the confining pressure. In other words, $\sigma_{\mathrm{cd}}$ and $\sigma_{f}$ of the specimen under the natural state are more sensitive to the confining pressure than those of the saturated sandstone.

3.2.3. Energy Conversion Characteristics. In uniaxial compression, only the axial load contributes to the work. However, in triaxial compression, the constant confining pressure also does the work on the specimen. Based on (1) (9), the energy conversion in the triaxial compression can be calculated and is shown in Figure 9.

Figure 9 shows the energy conversion of natural-state and saturated sandstone specimens under the confining pressures of $15 \mathrm{MPa}$ and $45 \mathrm{MPa}$. It can be seen by comparing Figures 5 , 9(a), and 9(b) that under a relatively low confining pressure (15 MPa) the prepeak change patterns of each type of the strain energy are similar to those in the uniaxial compression. However, in the postpeak region, the total strain energy increases relatively slowly, because the postpeak hoop strain is relatively large under the effect of the confining pressure in triaxial compression and so is the negative work done by the confining pressure. Under the confining pressure of $45 \mathrm{MPa}$, because no brittle failure occurs, no dramatic change happens to any type of the strain energy under two states. Instead, they change slowly and the change rates of each type of the strain energy reach equilibrium after entering the residue strength region, as is shown in Figures 9(c) and 9(d). Accordingly, it is safe to draw the conclusion that the confining pressure has significant effects on the energy conversion of sandstone constituents. Moreover, it is found that all types of the strain energy under the natural state surpass those under the saturated state, which means, like in the uniaxial compression, water suppresses the strain energy absorption in triaxial compression [19]. Besides, as an undrained procedure is adopted for the triaxial compression test (mainly because sandstones involved in underground projects like tunnels are 


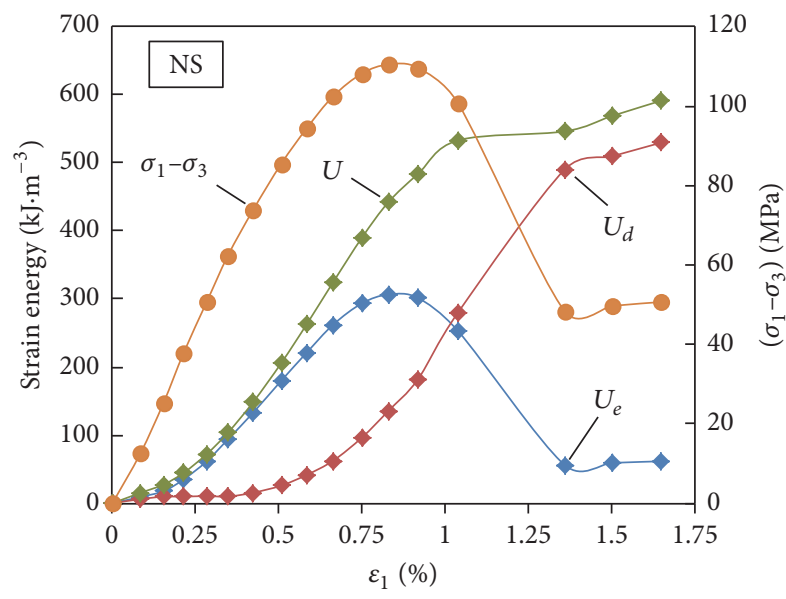

(a) I-4 (15 MPa)

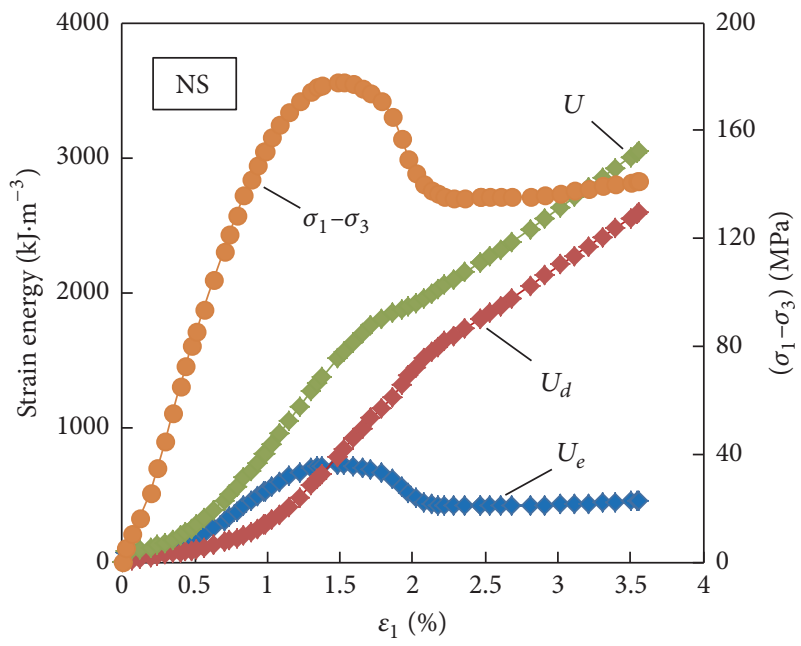

(c) I-7 (45 MPa)

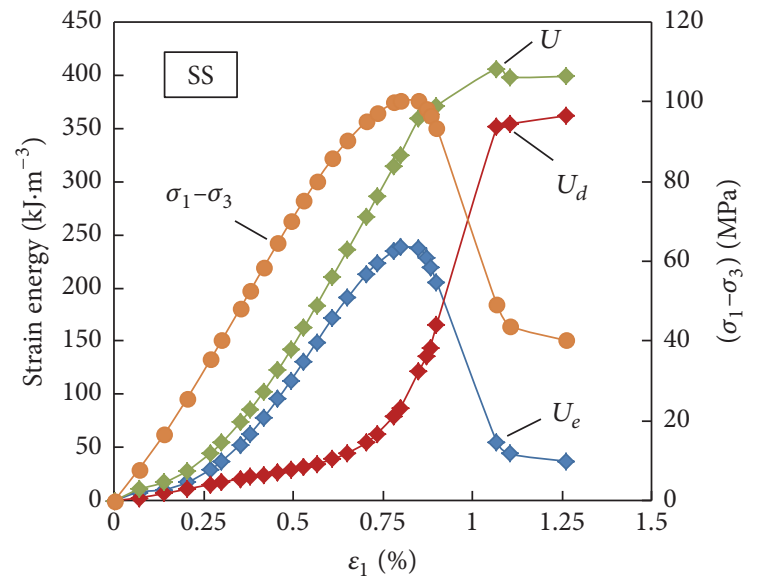

(b) II-4 (15 MPa)

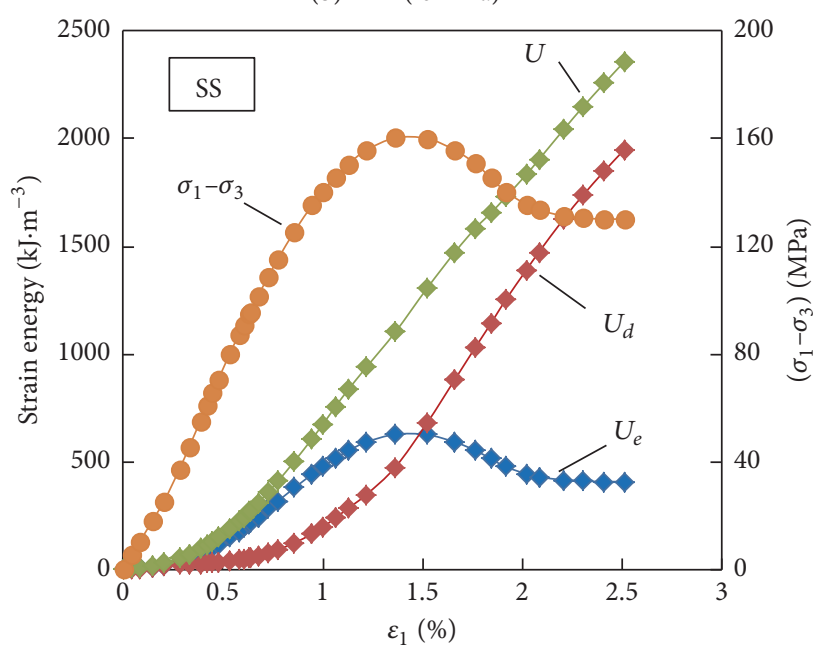

(d) II-7 (45 MPa)

FIGURE 9: The energy conversion curves of triaxial compression tests.

mostly located in an enclosed environment), although the saturated specimen has reasonable permeability coefficient for dissipation of water inside the rock, this process is in fact suppressed by the confining pressure and axial pressure. Under the effect of water, cracks inside the sandstones can more easily propagate and link each other, which will be discussed in detail in Section 4.

For better understanding of the effects of the confining pressure on the strain energy at the peak point, the relationships between the elastic strain energy $U_{e}$, the dissipated energy $U_{d}$, and the total strain energy $U$ and the confining pressure are analyzed and fitted, as is shown in Figure 10.

The following can be seen from Figure 10:

(1) For the natural-state specimen, $U_{e}, U_{d}$, and $U$ at the peak point all exceed those of the saturated specimen, which means that water can reduce the absorption of all kinds of strain energy in triaxial state of stress.

(2) $U_{e}, U_{d}$, and $U$ at the peak point under the two states all grow with the increase in confining pressure. Moreover, the fitting results suggest that good linear correlations exist between each type of strain energy and the confining pressure.

(3) The slopes of the fitting curves of $U_{e}, U_{d}$, and $U$ at the peak point of the natural-state specimen are all larger than those of saturated sandstones, and the increase rates of the former are also higher than those of the latter, which is similar to the change trend of $\sigma_{\mathrm{cd}}$ and $\sigma_{f}$ discussed in Section 5(2). This suggests that the strain energy of any kind is more sensitive to the confining pressure under the natural state than that under the saturated state. This phenomenon also shows that under high-stress conditions, for underground projects like tunnel construction, rockburst is more likely to happen to sandstones under natural states, while water saturation reduces the odds of rockburst. However, the potential risks of water inrush and burst in saturated sandstones cannot be neglected.

\section{Discussion}

Rocks are composed of multiple types of mineral compositions, and the mineral compositions vary in different rocks, 


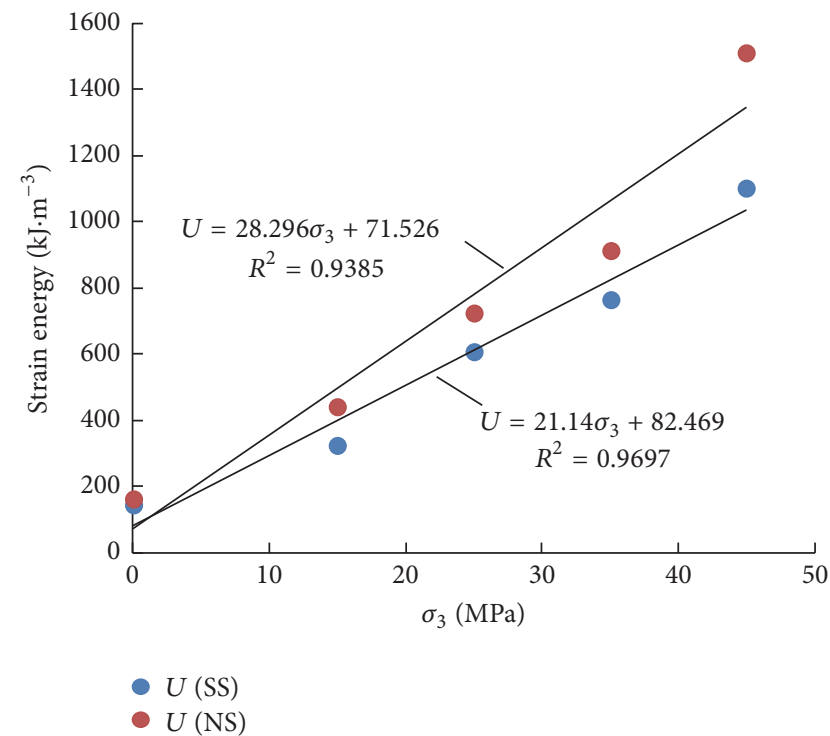

(a) $U$

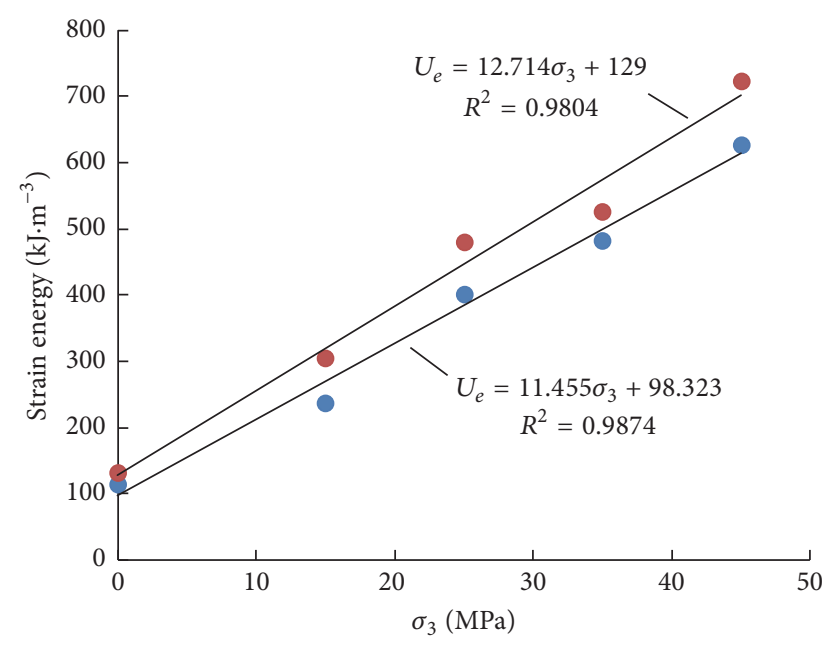

- $U_{e}(\mathrm{SS})$

- $U_{e}(\mathrm{NS})$

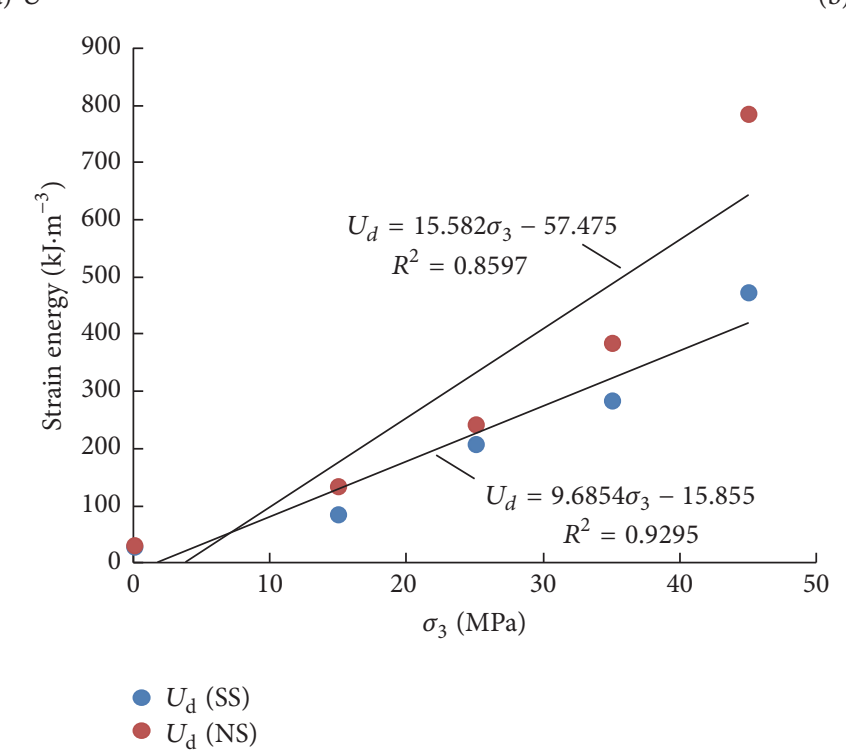

(b) $U_{e}$

FIGURE 10: Relationships between the strain energy at the peak point and the confining pressure under natural and saturated states.

which leads to varying performance of rock encountering water. In this paper, the mineral composition of the tested sandstone specimen was measured using the polarizing microscope, with an Olympus Bh-2 type instrument. The sample is identified to be medium-fine grained feldspar sandstones, and the sample is composed of $50 \%$ of quartz, $40 \%$ of feldspar, $5 \%$ of lithic fragment, $1 \%$ of mica, and $4 \%$ of chlorites. The powdered rock samples have been through $\mathrm{X}$-ray diffraction (XRD) analyses using the PANalytical X' Pert Powder, and the results are shown in Figure 11. It is shown that the main minerals are quartz and feldspar, which is in accordance with the result of the polarizing microscope analysis.

Under the effect of water saturation, the bonding among particles decreases due to the corrosion of the cement of the rock and the dissolution of the mineral substance. To explain this effect, the scanning electron microscope (SEM) analysis was conducted on natural and saturated sandstones, using the TESCAN VEGA II LMU. The results are shown in Figure 12.

It can be seen from Figure 12 that, on the one hand, natural sandstones have a relatively even distribution of the grain size and is more homogenous. Most of the particles are single and flat, and the cementation between particles is tight, with small pores scattered. On the other hand, as for saturated sandstones, the grains change from flat to flaky, and the cementation material heaves, with weakening bonding and increasing pores.

The dissolution of the mineral substance generates extra pore space and fractures inside the sandstone and stimulates the expansion and propagation of existing pores and cracks. 


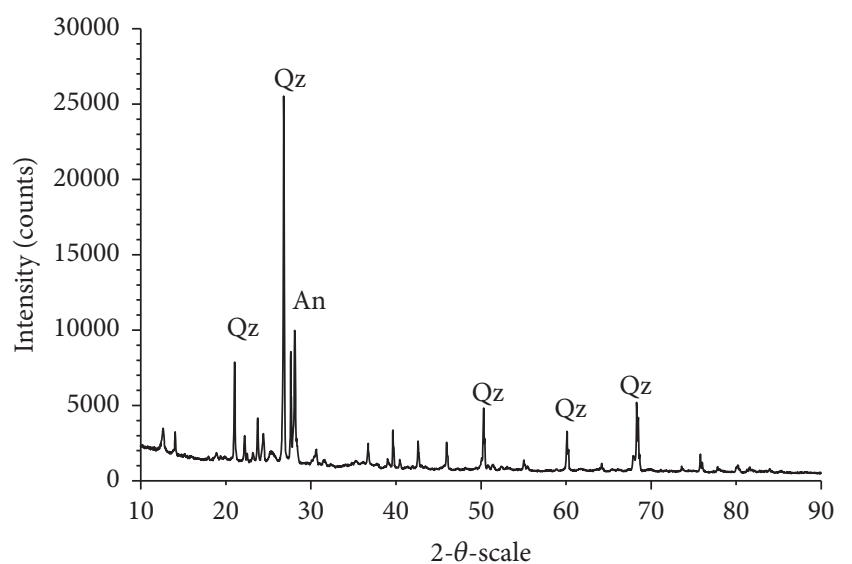

FIGURE 11: X-ray diffraction powder spectrum of the sandstone. $\mathrm{Qz}=$ quartz; An = anorthite.

For example, the feldspar is a kind of silicate minerals, with a negatively charged spatial structure. When it encounters and hydrolyzes with water, its ductility and compressibility intensify and strength reduces due to the chemical effect of water. Relevant discussion can be seen in the studies of Hawkins and McConnell [4], Atkinson [26], and Li et al. [27].

Meanwhile, more water will enter and fill pores and cracks, which accelerates the erosion of the micro crack tip, increases the tip stress, and prompts the further development of deterioration. This phenomenon can be explained with the sliding model describing the propagation of wing cracks. It is assumed that the friction and normal stress on the crack plane meet the Mohr-Coulomb criterion. When the shear stress on the crack plane caused by the external load exceeds the friction, the crack plane will slide and thus stress concentration will occur at the crack tip, which at last leads to formation and extension of wing cracks. Relevant studies have been conducted by Horii and Nemat-Nasser [28] and Steif [29]. Supposing the saturated specimen is triaxially compressed, the sliding model is shown in Figure 13.

With $\sigma_{1}$ and $\sigma_{3}$ applied to the saturated sandstone, the shear stress $\tau_{\mathrm{sw}}$ and normal stress $\sigma_{\mathrm{sw}}$ are generated on the initial crack. During the triaxial compression process, the water inside the rock cannot move out completely within a sufficiently short time, under the constraints imposed by the confining pressure and axial load in the undrained setting, although the sandstone has reasonable permeability coefficients. The initial crack inside the rock is closed due to the compression, which leads to the pore pressure in free water. Oshita and Tanabe [31] showed that the correlation between the pore pressure and the increase in the external load is linear. As the load rises, wing cracks occur and water spreads towards the crack tips. At this moment, a stress $p_{\text {sw }}$ occurs inside the crack, increases the stress at the crack tip, and accelerates the crack propagation and ultimately the failure of the rock, of which similar description can be found in the studies of Guo et al. [19], Atkinson and Cook [25], and Wang and $\mathrm{Li}$ [30]. Accordingly, influenced by the water softening and the accelerating effect of water on the crack propagation of the internal crack, the strength of saturated sandstones can be lowered below that of specimens under natural states. This also explains the strength deterioration mechanism of sandstones under the undrained triaxial compression condition, which is mentioned in Section 3.2.3.

Moreover, the presence of water enhances the molecule activity, which also impacts the deformation and strength of rock. Under the loading effects of the axial load and confining pressure, the water inside the rock generates pore pressure, which will offset part of the total stress applied on any internal surface of rock, decrease the elasticity limit as well as the shear strength, and at last lead to shear failure. K. Terzaghi first proposed the effective stress theory for soil materials, and M. A. Biot [32] modified Terzaghi's theory:

$$
\sigma_{i j}^{\prime}=\sigma_{i j}-b p_{w} \delta_{i j}
$$

where $\sigma_{i j}$ is the stress tensor; $\sigma_{i j}^{\prime}$ is the effective stress tensor; $p_{w}$ is the pore pressure; $\delta_{i j}$ is a second-order unit sensor, satisfying $\delta_{i j}=1(i=j)$ and $\delta_{i j}=0(i \neq j) ; b$ is Biot's coefficient, which can be determined as follows:

$$
b=1-\frac{K}{K_{s}},
$$

where $K$ and $K_{s}$ are, respectively, the bulk modulus of the solid particle of rock and the rock matrix. Biot's coefficient depends on the development of the pore and fracture of the rock, and $0 \leq b \leq 1$.

The deformation and failure mechanism of rock under natural and saturated sates can be explained based on the effective stress theory [33-35] and the Mohr-Coulomb theory. The Mohr-Coulomb theory, representing the rock failure, can be described as

$$
\tau=\sigma \tan \varphi+c
$$

When the pore pressure is applied on the pore and fracture of rock, the effective normal stress is $\sigma^{\prime}=\sigma-b p_{w}$, and the rock strength can then be calculated using the following equation:

$$
\tau=\left(\sigma-b p_{w}\right) \tan \varphi+c=\sigma \tan \varphi+\left(c-b p_{w} \tan \varphi\right) .
$$

Equation (14) can be rearranged into

$$
\tau=\sigma \tan \varphi+c_{w}
$$

where $c_{w}$ is the cohesion of saturated rock and

$$
c_{w}=\left(c-b p_{w} \tan \varphi\right) .
$$

Similarly, the compressive strength of rock under the effect of water can be described as

$$
R_{w}=R_{c}-\frac{2 b p_{w} \sin \varphi}{1-\sin \varphi} .
$$

The above theoretical analysis validates that the cohesion, shear strength, and compressive strength of rock decrease due to the pore pressure generated by the water inside the saturated sandstone specimen loaded because of the axial 


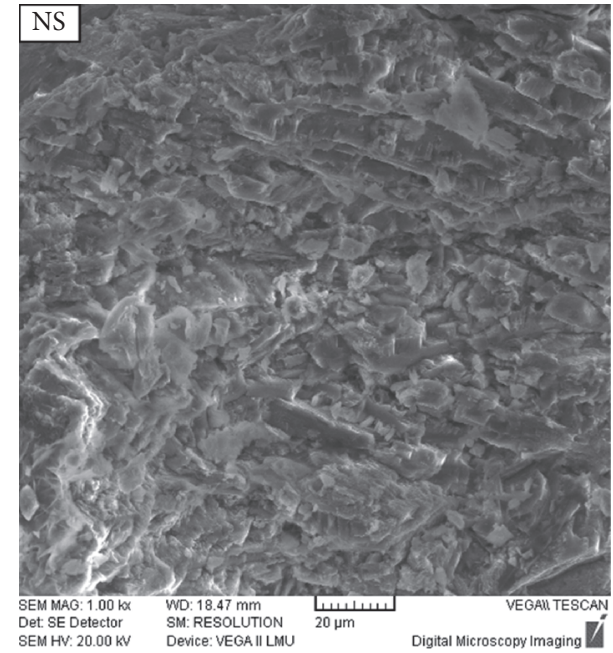

(a)

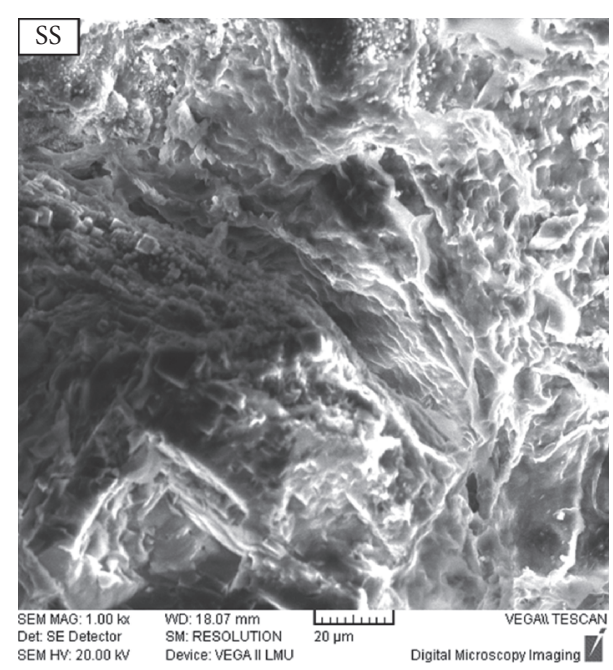

(b)

FIGURE 12: SEM graphics of natural and saturated sandstones.

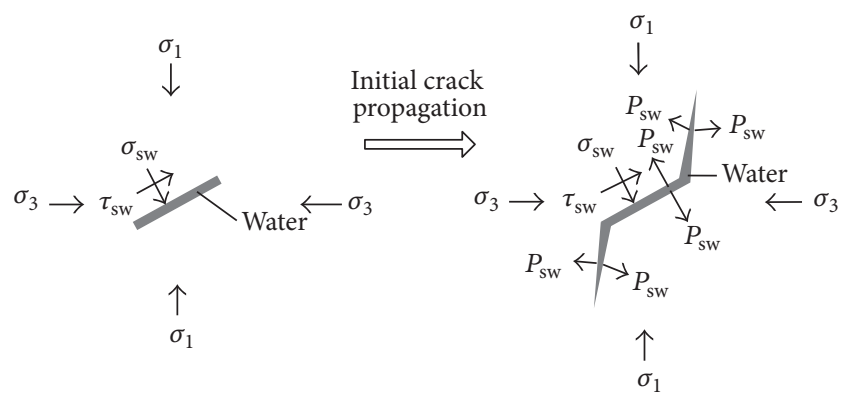

FIGURE 13: Crack sliding model under saturated states [30].

load and the confining pressure. This analysis provides a fundamental way to explain the deterioration mechanism of relevant mechanical properties of rock after saturation. Since all types of the strain energy are calculated based on the mechanical parameters of the specimen in different regions of the test process, the mechanism of deterioration is similar and not discussed in detail here.

\section{Conclusions}

(1) The sandstone specimens under both natural and saturated states exhibit apparent brittleness in the uniaxial compression test. Water saturation has great effects on the sandstone constituent strength and deformation characteristics, and the load bearing capacity and nondeformability reduce after water saturation. In the triaxial compression test, the equivalent softening coefficients $\eta_{c}^{\prime}$ under all of the confining pressures exceed that in the uniaxial compression test. The strength weakening effect of water in the saturated specimen mainly works after the dilatancy stress $\sigma_{\text {cd }}$ and reaches its top level at the peak stress $\sigma_{f}$. Hence, during projects such as tunnel excavation, sandstones under saturated states should be timely supported, so that the stress can be limited within a relatively low range and the tunnel instability followed by water inrush and burst be avoided.

(2) For both the natural-state and saturated specimens, in the prepeak region most of the absorbed energy is stored as $U_{e}$ and only a small part goes to $U_{d}$, while in the postpeak region $U_{d}$ increases rapidly. All kinds of the strain energy under the saturated state are lower than those under the natural state, which indicates that water reduces the absorption of all kinds of strain energy. Although the energy conversion patterns under the two states are similar, the change rate of each kind of strain energy with the increase in the axial strain varies greatly in different regions of the whole process. With the natural and saturated states of sandstones concerned, the support scheme should change in line with the rock state during the tunnel excavation process, in order to ensure the stability of the surrounding rock.

(3) In conventional triaxial tests under a relatively low confining pressure $(15 \mathrm{MPa})$, the prepeak change patterns of all kinds of strain energy under natural and saturated states are similar to those in uniaxial compression, while in the postpeak region, the negative work done by the confining pressure slows down the growth of the total strain energy $U . U_{e}, U_{d}$, and $U$ at the peak point of the natural-state specimen are all higher than those of saturated specimens. The three kinds of strain energy at the peak point linearly increases with growth in the confining pressure under the two states, and moreover the slopes of the fitting curves of the natural-state cases are higher than those of the saturated cases, which suggests a greater 
sensitivity of the strain energy to the confining pressure. Under high-stress conditions, for underground projects like tunnel construction, rockburst is more likely to happen to sandstones under natural states, while water saturation reduces the odds of rockburst. However, the potential risks of water inrush and burst in saturated sandstones cannot be neglected.

(4) The deterioration of sandstone constituents aroused by water is mainly because of decreasing bonding among particles led by the corrosion of cement materials and the dissolution of mineral substances. Moreover, water inside the specimen generates the pore pressure under the loading effect of the axial load and confining pressure and hence also decreases the rock strength.

\section{Competing Interests}

The authors declare that there is no conflict of interests regarding the publication of this paper.

\section{Authors' Contributions}

Jun Liu organized the experimental procedure and results and paper writing. Xinrong Liu helped with the experimental procedure and analyzed the measured results.

\section{Acknowledgments}

This study is supported by Scientific Research Foundation of State Key Lab of Coal Mine Disaster Dynamics and Control (Project no. 2011DA105287-MS201208), the Fundamental Research Funds for Central Universities of China (Project no. CDJXS12201106), and the Natural Science Foundation of Chongqing, China (Project no. cstc2013jcyjA30005). Zuliang Zhong, Dongliang Li, and Zijuan Wang proofread the manuscript and polished the language. The authors gratefully acknowledge these supports.

\section{References}

[1] D.-X. Liang, Z.-Q. Jiang, S.-Y. Zhu, Q. Sun, and Z.-W. Qian, "Experimental research on water inrush in tunnel construction," Natural Hazards, vol. 81, no. 1, pp. 467-480, 2016.

[2] S. Ling, Y. Ren, X. Wu, S. Zhao, and L. Qin, "Study on reservoir and water inrush characteristic in Nibashan Tunnel, Sichuan Province, China," Engineering Geology for Society and Territory, vol. 246, no. 1, pp. 710-715, 2015.

[3] L. Shi and R. N. Singh, "Study of mine water inrush from floor strata through faults," Mine Water and the Environment, vol. 20, no. 3, pp. 140-147, 2001.

[4] A. B. Hawkins and B. J. McConnell, "Sensitivity of sandstone strength and deformability to changes in moisture content," Quarterly Journal of Engineering Geology, vol. 25, no. 2, pp. 115130, 1992.

[5] B. Vasarhelyi, "Some observations regarding the strength and deformability of sandstones in dry and saturated conditions," Bulletin of Engineering Geology and the Environment, vol. 62, no. 3, pp. 245-249, 2003.
[6] B. Vásárhelyi and P. Ván, "Influence of water content on the strength of rock," Engineering Geology, vol. 84, no. 1-2, pp. 7074, 2006.

[7] O. Sass, "Rock moisture measurements: techniques, results, and implications for weathering," Earth Surface Processes \& Landforms, vol. 30, no. 3, pp. 359-374, 2005.

[8] R. E. Thill, T. R. Bur, and R. C. Steckley, "Velocity anisotropy in dry and saturated rock spheres and its relation to rock fabric," International Journal of Rock Mechanics and Mining Sciences and, vol. 10, no. 6, pp. 535-557, 1973.

[9] L. Louis, C. David, and P. Robion, "Comparison of the anisotropic behaviour of undeformed sandstones under dry and saturated conditions," Tectonophysics, vol. 370, no. 1-4, pp. 193212, 2003.

[10] H.-P. Xie, Y. Ju, and L.-Y. Li, "Criteria for strength and structural failure of rocks based on energy dissipation and release principles," Chinese Journal of Rock Mechanics and Engineering, vol. 24, no. 17, pp. 3003-3010, 2005.

[11] D. Huang and Y. Li, "Conversion of strain energy in triaxial unloading tests on marble," International Journal of Rock Mechanics and Mining Sciences, vol. 66, pp. 160-168, 2014.

[12] Z. X. Zhang, S. Q. Kou, L. G. Jiang, and P.-A. Lindqvist, "Effects of loading rate on rock fracture: fracture characteristics and energy partitioning," International Journal of Rock Mechanics and Mining Sciences, vol. 37, no. 5, pp. 745-762, 2000.

[13] M. Lindqvist, "Energy considerations in compressive and impact crushing of rock," Minerals Engineering, vol. 21, no. 9, pp. 631-641, 2008.

[14] C. E. Tsoutrelis and G. E. Exadaktylos, "Effect of rock discontinuities on certain rock strength and fracture energy parameters under uniaxial compression," Geotechnical and Geological Engineering, vol. 11, no. 2, pp. 81-105, 1993.

[15] X. P. Zhou, "Triaxial compressive behavior of rock with mesoscopic heterogenous behavior: strain energy density factor approach," Theoretical and Applied Fracture Mechanics, vol. 45, no. 1, pp. 46-63, 2006.

[16] Y. Nara and K. Kaneko, "Sub-critical crack growth in anisotropic rock," International Journal of Rock Mechanics and Mining Sciences, vol. 43, no. 3, pp. 437-453, 2006.

[17] M. N. Bagde and V. Petroš, "Fatigue and dynamic energy behaviour of rock subjected to cyclical loading," International Journal of Rock Mechanics and Mining Sciences, vol. 46, no. 1, pp. 200-209, 2009.

[18] L.-M. Zhang, S. Gao, and Z.-Q. Wang, "Experimental study of energy evolution of limestone under loading and unloading conditions," Rock and Soil Mechanics, vol. 34, no. 11, pp. 30713076, 2013.

[19] J. Guo, X. Liu, and C. Qiao, "Experimental study of mechanical properties and energy mechanism of karst limestone under natural and saturated states," Chinese Journal of Rock Mechanics and Engineering, vol. 33, no. 2, pp. 296-308, 2014.

[20] American Society for Testing and Materials, Standard Test Methods for Compressive Strength and Elastic Moduli of Intact Rock Core Specimens Under Varying States of Stress and Temperatures: D7012-14, Annual Book of ASTM, Philadelphia, Pa, USA, 2014.

[21] E. T. Brown and E. Hoek, "Trends in relationships between measured in-situ stresses and depth," International Journal of Rock Mechanics and Mining Sciences and, vol. 15, no. 4, pp. 211215, 1978. 
[22] F. Jing, Q. Sheng, Y. Zhang, C. Luo, and Y. Liu, "Research on distribution rule of shallow crustal geostress in China mainland," Chinese Journal of Rock Mechanics and Engineering, vol. 26, no. 10, pp. 2056-2062, 2007.

[23] Z. T. Bueniawski, "Mechanism of brittle fracture of rock, Parts I,II and III," International Journal of Rock Mechanics and Mining Sciences, vol. 4, no. 4, pp. 395-430, 1967.

[24] M. Cai, P. K. Kaiser, Y. Tasaka, T. Maejima, H. Morioka, and M. Minami, "Generalized crack initiation and crack damage stress thresholds of brittle rock masses near underground excavations," International Journal of Rock Mechanics and Mining Sciences, vol. 41, no. 5, pp. 833-847, 2004.

[25] C. Atkinson and J. M. Cook, "Effect of loading rate on crack propagation under compressive stress in a saturated porous material," Journal of Geophysical Research, vol. 98, no. 4, pp. 6383-6395, 1993.

[26] B. K. Atkinson, "Subcritical crack growth in geological materials," Journal of Geophysical Research, vol. 89, no. 6, pp. 40774114, 1984.

[27] P. Li, J. Liu, G.-H. Li, J.-B. Zhu, and S.-G. Liu, "Experimental study for shear strength characteristics of sandstone under water-rock interaction effects," Rock and Soil Mechanics, vol. 32, no. 2, pp. 380-386, 2011.

[28] H. Horii and S. Nemat-Nasser, "Brittle failure in compression: splitting, faulting and brittle-ductile transition," Philosophical Transactions of the Royal Society A: Mathematical, Physical and Engineering Sciences, vol. 319, no. 1549, pp. 337-374, 1986.

[29] P. S. Steif, “Crack extension under compressive loading," Engineering Fracture Mechanics, vol. 20, no. 3, pp. 463-473, 1984.

[30] B. Wang and X.-B. Li, "Mesomechanics analysis of static compressive strength and dynamic compressive strength of watersaturated rock under uniaxial load," Explosion and Shock Waves, vol. 32, no. 4, pp. 423-431, 2012.

[31] H. Oshita and T. Tanabe, "Water migration phenomenon in concrete in prepeak region," Journal of Engineering Mechanics, vol. 126, no. 6, pp. 565-572, 2000.

[32] M. A. Biot, "General theory of three-dimensional consolidation," Journal of Applied Physics, vol. 12, no. 2, pp. 155-164, 1941.

[33] S. Ghabezloo, J. Sulem, S. Guédon, and F. Martineau, "Effective stress law for the permeability of a limestone," International Journal of Rock Mechanics \& Mining Sciences, vol. 46, no. 2, pp. 297-306, 2009.

[34] O. Kwon, A. K. Kronenberg, A. F. Gangi, and B. Johnson, "Permeability of Wilcox shale and its effective stress law," Journal of Geophysical Research, vol. 106, no. 9, pp. 19339-19353, 2001.

[35] Z. P. Meng, J. N. Pan, L. L. Liu, G. X. Meng, and Z. H. Zhao, "Influence of moisture contents on mechanical properties of sedimentary rock and its bursting potential," Chinese Journal of Rock Mechanics and Engineering, vol. 28, supplement 1, pp. 2637-2643, 2009. 

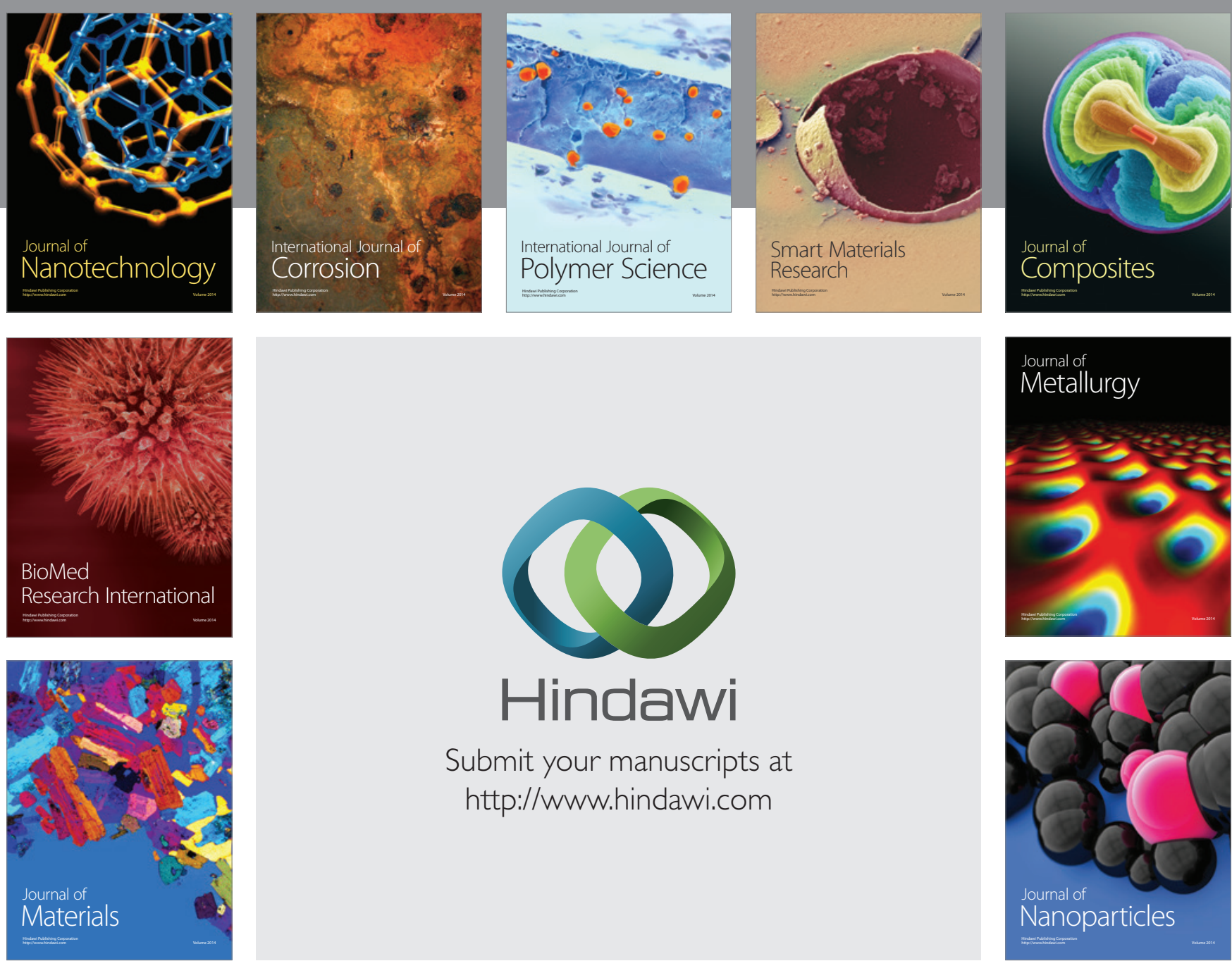

\section{Hindawi}

Submit your manuscripts at

http://www.hindawi.com

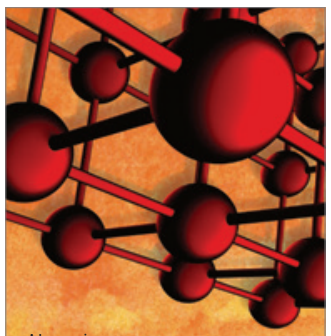

Materials Science and Engineering
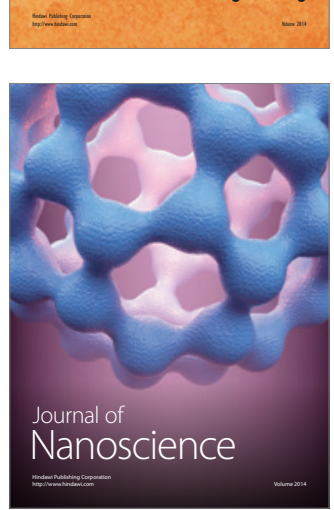
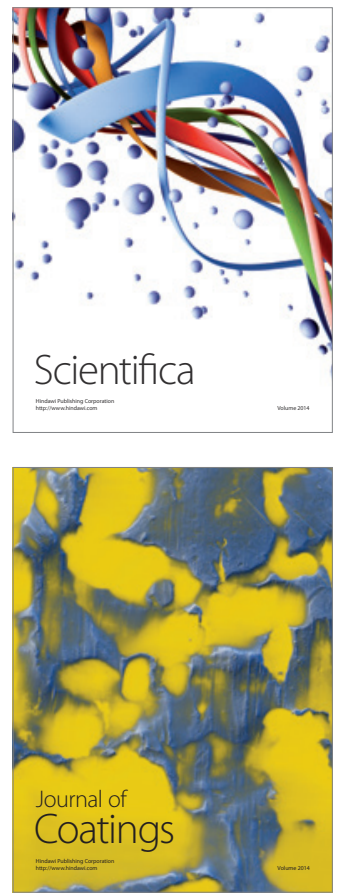
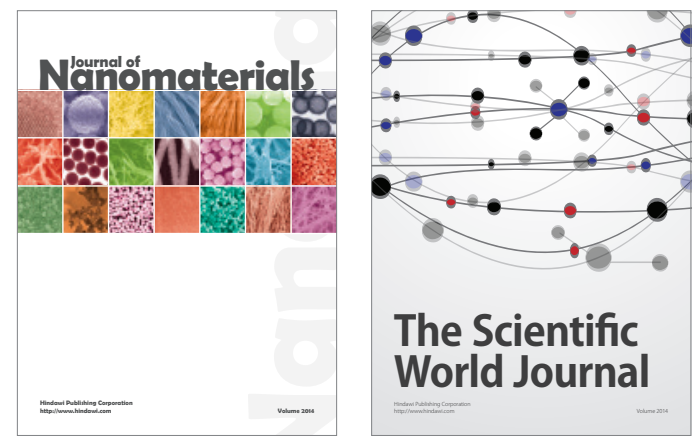

The Scientific World Journal
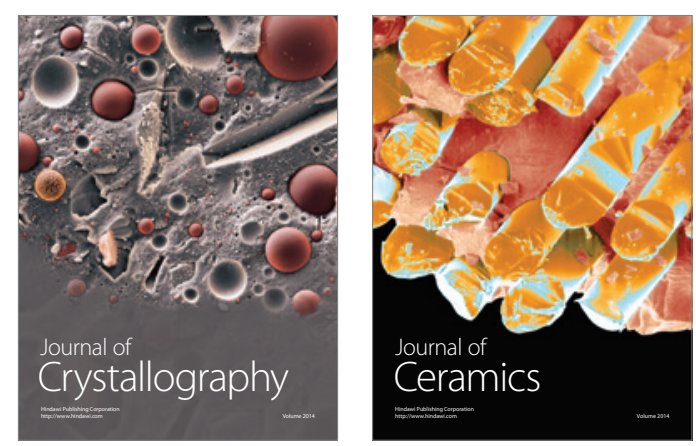
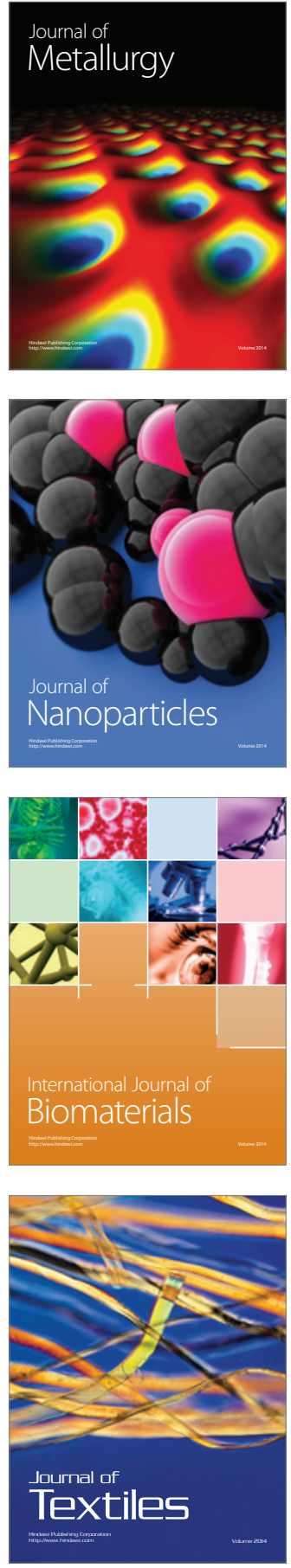